\title{
Private asset income in France: Is there a breakdown of intergenerational equity between 1979 and 2011?
}

\author{
Hippolyte d'Albis, ${ }^{1}$ Ikpidi Badji, ${ }^{2}$ Najat El Mekkaoui, ${ }^{3}$ Julien Navaux ${ }^{4}$
}

\begin{abstract}
We use the National Transfer Accounts methodology to calculate private asset income by age for the years 1979-2011. We analyze age profiles using three indicators of intergenerational equity. Monetary asset income shows no evidence of generational breaks to the benefit of the baby-boom generation. On the contrary, baby-boomers suffered from the high interest rates that they paid to become homeowners. Imputed rents show an obvious breakdown of intergenerational equity when we use an inter-age and intergenerational indicator. This indicator compares the per capita asset income at a given age with the average asset income of people aged 18-85. It gives the relative situation of one age group compared to its contemporaries and it also gives the relative situation of one generation when we compare birth cohorts over time. We find that the cohort born in 1950 benefited from a better position than their successors. Moreover, the cohorts born before the war and during the war appear to be even more favored than the baby-boomers. The cohorts born in 1930 and in 1940 have a better situation than the previous generations and a better position than the following generations.
\end{abstract}

Keywords. National Transfer Accounts; Private Asset Income; Intergenerational Equity.

JEL codes. E01; E21; D14.

\footnotetext{
${ }^{1}$ Paris School of Economics, CNRS. E-mail: hdalbis@psemail.eu

${ }^{2}$ EconomiX-CNRS, Paris-Ouest Nanterre-La Défense University. E-mail: ikpidibadji@gmail.com

${ }^{3}$ Université Paris Dauphine. E-mail: najat.el-mekkaoui@dauphine.fr

${ }^{4}$ University of Ottawa. E-mail: jnavaux@uottawa.ca
} 


\section{Introduction}

The French PAYG system reached a peak in 2014. That year, public pensions accounted for $14.1 \%$ of GDP (Conseil d'Orientation des Retraites ${ }^{5}$, 2017). From 2014 forward, that share should progressively fall, provided that the GDP growth rate maintains an acceptable level. If the GDP growth rate remains stable at $1.3 \%$, pensions could account for $13.3 \%$ of GDP by 2050 . A higher growth rate would result in a smaller share of GDP - for example, with a stable 1.8\% growth rate, pensions as a share of GDP could fall to $12.1 \%$. Contrary to popular belief, France has in fact implemented pension reforms to address the issue of population aging. Although the reforms were justified on grounds of sustainability, they will be costly for the pensioners. Replacement rates will decrease strongly from the 1950's birth cohorts. Whereas a 68-year-old born in 1947 could count on a replacement rate of 54.3\%, a 68-year-old born in 1980 will see his replacement rate fall to $47.5 \%{ }^{6}$. Consequently, future pensioners will have to find a solution to the conundrum: how to maintain its consumption level over time as public pensions decline. Should they rely on their families or on themselves? Family solidarity with transfers from younger generations to older generations is not a realistic solution in France. Nowadays, the direction of family transfers is the opposite. French pensioners transfer a net amount equivalent to $0.9 \%$ of GDP to younger generations ${ }^{7}$. However, given that pensioners concentrate more assets than younger generations, another solution may come from retirees' assets.

In 2011, private asset income accounted for $17.1 \%$ of GDP, i.e. 3.6 points higher than public pensions for the same year, and the share of private asset income received by persons aged 60+ was $47.5 \%$. However, French pensioners suffered from the low interest rates implied by the monetary policy of the European Central Bank. In 2016, long-term interest rates were lower than $0.47 \%$ in France, while they were higher than $1.8 \%$ in the USA.

In a nutshell, future pensioners could suffer from pension reforms without any guarantee of benefiting from higher rates of return on their assets. It should be pointed out that the consumption level of pensioners is not restricted to monetary flow. It also includes imputed rents that are a significant part of private asset income. In 2011, rents accounted for $30.3 \%$ of total private asset income. Moreover, the share of homeownership increased significantly for people aged 50 and over

\footnotetext{
${ }^{5}$ Institution that advises the French prime minister for the public pension system.

${ }^{6}$ With annual productivity gains of $1.3 \%$.

${ }^{7}$ Data from the National Transfer Accounts for France in 2011.
} 
between 1986 and 2010 (Arrondel et al., 2011). This increase was even greater for people aged 70 and over. People who bought their first home before the price boom that started in the late 1970s also benefited from a strong leverage effect.

We expect that the combined effects of pension reforms, housing prices, and the economic climate will strongly modify the allocation of asset income across generations. In France, the most recent studies on the allocation of consumption and labor income (d'Albis et al., 2017; d'Albis and Badji, 2017), on public transfers (Chojnicki et al., 2016; Navaux, 2016), and on financial wealth (Bernard and Berthet, 2015) showed no evidence of an intergenerational break to the benefit of the baby-boomers. However, these studies do not address the issue of the allocation of private asset income between age groups and generations.

Our study is focused on all these aspects of asset income. It deals with economic flows and with imputed rents. We use the National Transfer Account (NTA) methodology to investigate the issue of intergenerational equity. We introduce age profiles for financial and real estate income, household interest rates, capital income of self-employed individuals, and for imputed rents. The French NTA project has been conducted with the aim of measuring time series over the longest period, i.e. between 1979 and 2011. On this note, France has now joined the small group of countries that have constructed NTA time series, such as the United States (Donehower et al., 2011), Sweden (Lindh et al., 2011), Taiwan (Lai and Tung, 2015), and Australia (Temple et al., 2017). Access to long term time series for French age profiles is a necessary prerequisite for comparing several generations at the same age.

We introduce three indicators of intergenerational equity with the aim of obtaining a broad analysis of intergenerational differences. The first indicator describes the relative situation of an age group with respect to the situation of another age group over time. Our second indicator compares the standard of living of successive generations at the same age. The third indicator is a combination of the two previous criteria. It is both an inter-age indicator and also an intergenerational indicator. It computes relative measures of income by dividing net resources at age $a$ and date $t$ by their cross-sectional average.

This paper is organized as follows. The first section describes NTA methodology and the data sources for the age profiles. The second section introduces the three intergenerational equity indicators that we selected to analyze the NTA profiles. The third and the fourth sections present the empirical results for monetary asset income (section 3 ) and for imputed rents (section 4) and the last section concludes. 


\section{Methodology and data}

NTA is an international project whose purpose is to "improve understanding of how population growth and changing population age structure influence economic growth, gender and generational equity, public finances, and other important features of the macro-economy" notably by creating National Accounts broken down by age. It computes age profiles using survey and administrative data that is readjusted by using aggregate controls drawn from National Accounts. The theoretical basis of the methodology is available in Lee and Mason (2011a, 2011b) and the detailed methodology for building those accounts is explained in a manual edited by the United Nations in 2013. Some recent developments using NTA are presented in d'Albis and Moosa (2015), d'Albis et al. (2017) and Temple et al. (2017).

Private asset income is broadly broken down between property income and capital income. Table 1 presents the detailed breakdown of the aggregate and gives the amount of the flows for 2011. In this article, we focus on income received by households and exclude those received by corporations and nonprofit institutions serving households (NPISHs). The computation of our two main variables, based on households' private property income and private capital income, is obtained as follows. Private property income of households includes financial asset income, which amounted to 113.2 billion euros in 2011, and real estate income (including those obtained from land), which amounted to 39.7 billion euros. Moreover, interest payments on loans are subtracted. In 2011, households gave 25 billion euros to corporations for that purpose. Private capital income of households includes two groups of income inflows: the private capital share of mixed income ${ }^{8}$, which represented 27.5 billion euros, and private capital income on owner-occupied housing, also referred to as imputed rents, which amounted to 106.6 billion euros. Thus, private capital incomes include both real flows (financial asset income, real estate income, interest, capital share of mixed income, and fictive flows (imputed rents).

\footnotetext{
${ }^{8}$ In the NTA methodology, the mixed income received by self-employed individuals is allocated between labor and capital. The NTA manual (United Nations, 2013) suggests separating the share of capital and labor in total earnings with a 1/3-2/3 rule in order to calculate the aggregate of each component. In France, we made a more precise evaluation of those aggregates using the method proposed by Askenazy et al. (2011). Our detailed methodology is presented in d'Albis et al. (2015).
} 
Table 1: Asset income in the NTA methodology-Aggregates for France, 2011 (billion €)

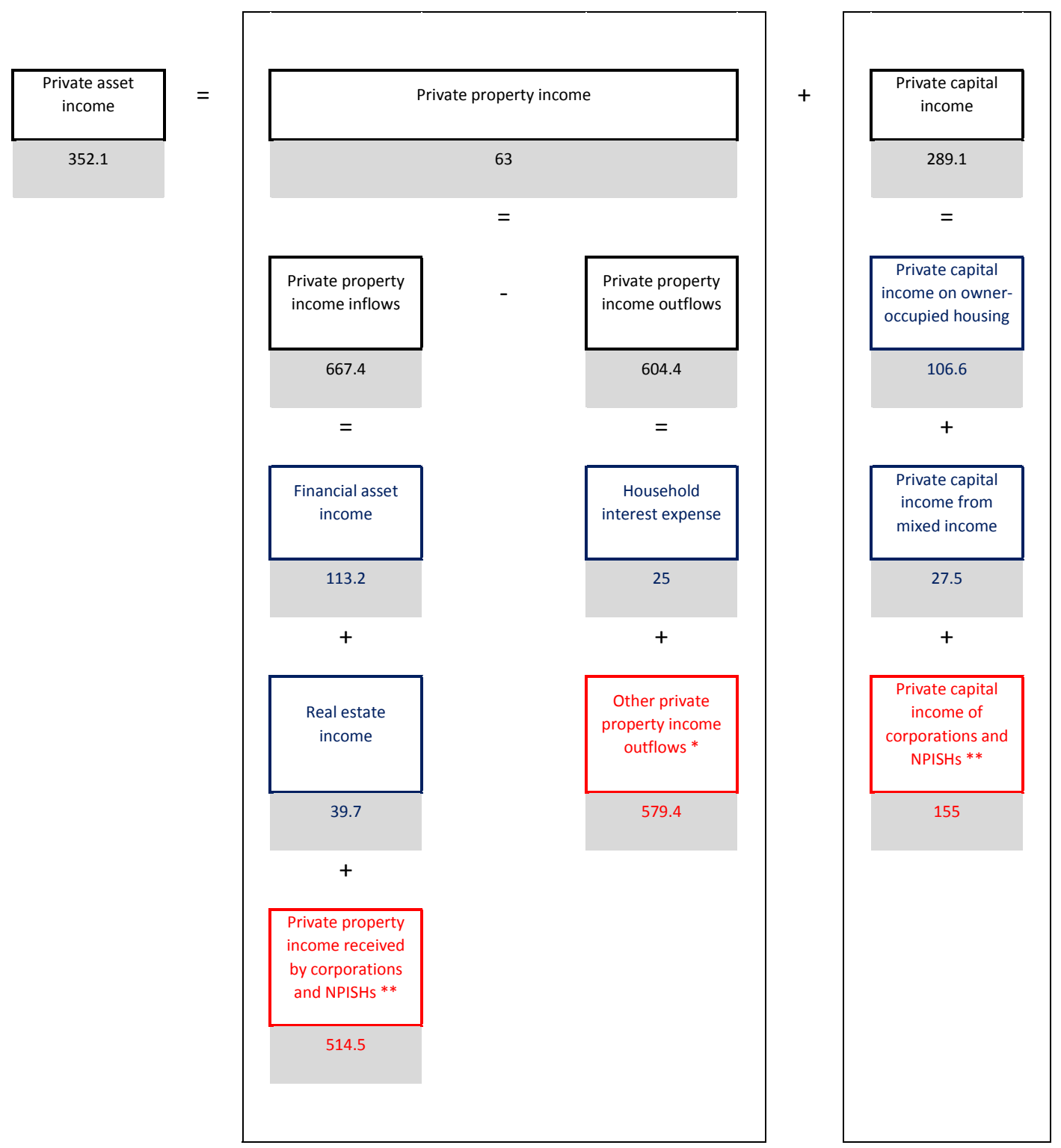

Source: authors' calculations, National Accounts (INSEE). Flows in red are those that are not considered in this article.

* Other private property income outflows include interests paid by corporations and NPISHs, dividend outflows from the corporations, royalties, and rents for land (out of housing rents) and deposits paid by non-financial corporations and households. Thus, a very small share of household private asset income is included in "other private property income outflows" but it cannot be attributed to individuals.

** Private property income received by corporations and NPISHs are generated from assets owned by corporations and NPISHs while private capital income of corporations and NPISHs are generated by corporations and NPISHs themselves. 
In what follows, we aggregate real flows in a single variable that we have called "monetary asset income", corresponding to an aggregate net amount of 155.4 billion euros in 2011, and we analyze the 106.6 billion euros of imputed rents separately.

Two different surveys are used to calculate the age profiles: the French Household Expenditures survey (Budget de famille) and The French Wealth survey (Actifs financiers and Patrimoine). Financial asset income, interests, the capital share of mixed income and imputed rents are taken from the Household Expenditure surveys conducted in 1978-1979, 1984-1985, 1989, 1994-1995, 2000-2001, 2005-2006 and 2010-2011. Real estate incomes are taken from the Wealth surveys conducted in 1986, 1991, 19971998, 2003-2004 and 2009-2010.

It should be mentioned that private income is reported at the household level (except mixed income that is available for each individual $)^{9}$ and the surveys give no information about the owner of each asset. According to NTA methodology, asset income inflows should be assigned to the household head. In order to provide a better individualization within the household, we choose to share each asset income equally among spouses. Unfortunately, the 1979 to 1995 expenditure surveys do not provide figures for imputed rent. We had to estimate them using the characteristics of housing. The procedure is similar to the one used in (d'Albis et al., 2015, 2017). The imputed rent of homeowners is calculated using the following equation:

$$
\text { Rent }_{i}=\exp \left(X_{i} \beta+\text { residual }_{i}\right)
$$

where $X_{i}$ is the vector of the variables (region, urban units, surface area, number of rooms, etc.) of the rent equation for observation $i$ and where $\beta$ is the vector of the estimated coefficients of the rent equation. This regression is conducted separately for houses and for apartments. In order to obtain correct rent distribution, the imputed residual must have the same distribution as the residuals taken from the rent equation. As the rent equation residuals are heteroscedastic and non-Gaussian, they cannot be expressed as a normal distribution. The appropriate residual imputation method is the Hot Deck method, which involves randomly selecting an estimated residual using the estimation from the rent equation. This residual is then imputed to housing "similar" to the one from which we selected the estimation residual and for which we have to calculate the imputed rent.

Once the average age profiles are calculated, we smooth each profile by using the (Friedman, 1984) method recommended in the NTA methodology (Appendix B of United Nations, 2013). We highlight the

\footnotetext{
${ }^{9}$ The shape of the age profile of the capital share of mixed income is equivalent to the shape of the labor share of mixed income, see d'Albis et al. $(2015,2017)$.
} 
fact that each survey provides distant waves from several years and that Expenditure and Wealth surveys were not conducted during the same years. Consequently, we chose to interpolate the variables for all ages using polynomial functions. One should note that the wealth surveys are not available for 1979 and 1985 or for 2011. Thus, it is impossible to use the polynomial smoother for the first and the last year of real estate income because the interpolation methodology requires obtaining observations between the years that we interpolate. ${ }^{10}$ We assume that the shape of the age profiles between 1979 and 1985 are equivalent to the shape of the year 1986 and the shape of the profile for the year 2011 is equivalent to that of 2010. Finally, we obtain NTA age profiles for each variable over a period of 32 years, from 1979 to 2011.

Figure 1 represents components of private asset income by age in 2011. Financial asset income rises up to 4,771 euros per capita and per year at 69 years of age and decreases slightly to 3,635 euros at 85 years of age. It remains stable thereafter. Real asset income increases up to age 66 , the age at which it reaches a peak of 1,471 euros, and remains stable after age 80 . The stability of financial asset income after 85 and of real asset income after 80 is not explained by the real shape of the age profiles. In fact, given the small number of observations at old age, the quality of the age profiles extracted from the surveys is very poor. Consequently, for each year we assume that the value of financial asset income after age 85 is equal to the value at age 85 and the value of real asset income after age 80 is equal to the value at age 80 . The age profiles of the capital share of mixed income and of interest do not exhibit the same limitations because they are concentrated on working age groups, for which we can obtain many observations. More precisely, the shape of mixed income follows an " $M$ " curve. The age profile reaches a first peak of 858 euros at age 47 and reaches a second higher peak of 1,246 euros at age 60. Imputed rents rise from the beginning of working life up to 43 years of age when it reaches a peak of 2,651 euros per year. Thereafter, imputed rents remain quite stable, as they fluctuate between 2,491 and 2,792 euros. Finally, interest income is greater than 500 euros between ages 29 and 55 .

\footnotetext{
${ }^{10}$ The same method was applied in France for the life cycle deficit (d'Albis et al., 2015, 2017).
} 
Figure 1: Breakdown of per capita private asset income in 2011

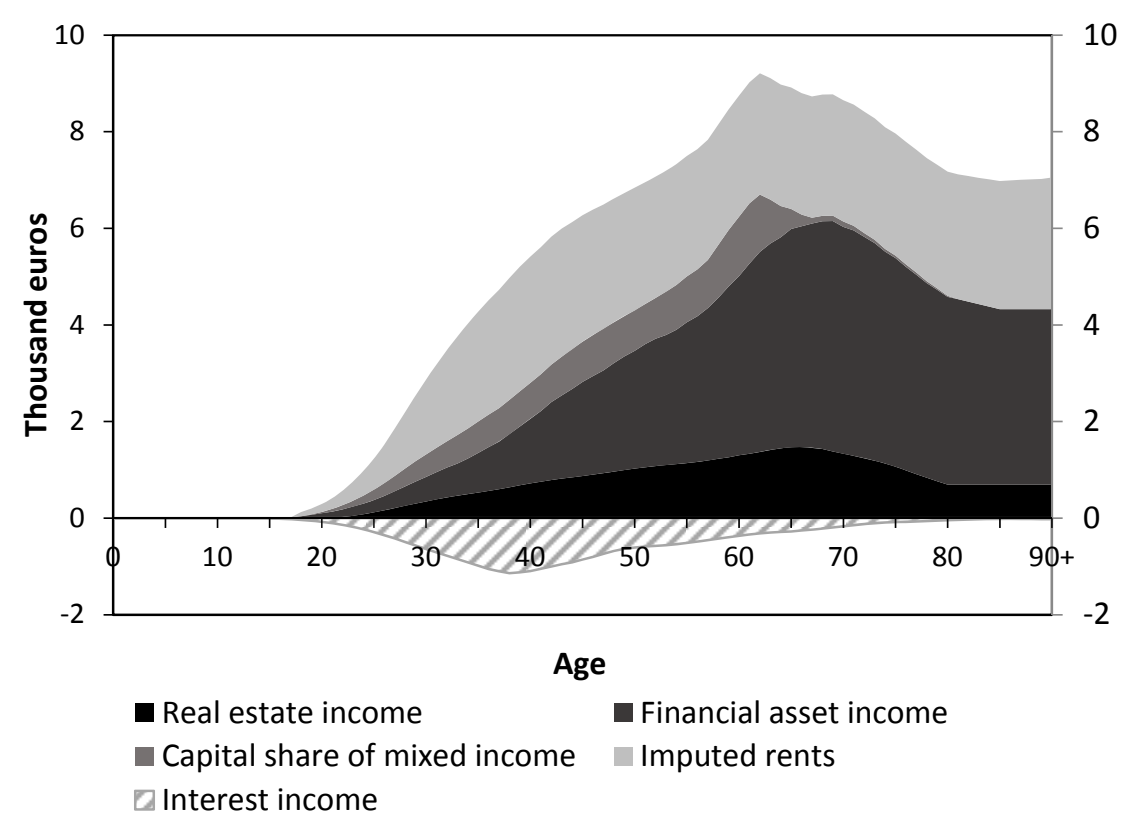

\section{Three indicators of intergenerational equity}

We selected three indicators of intergenerational equity with the aim of obtaining a broad analysis of intergenerational differences.

The first indicator describes the relative situation of retirees with respect to the situation of younger people. The evolution of this indicator over time is a way to evaluate intergenerational equity: in particular, a constant ratio can be interpreted as an indication of equity between age groups. This indicator provides a useful instantaneous picture, which describes the relative situation of two age groups at a given time (Blanchet, 1998). For instance, Navaux (2016) showed that in 2011, per capita public transfer inflows of French people aged 60 to 85 were 3.1 times higher than per capita public transfer inflows of French people aged 25 to 59 . The analysis of fluctuations of this ratio over time is also interesting. The baseline situation may be based on a stable age-to-age ratio as observed by Becker and Murphy (1988) for public transfer inflows between 1940 and 1983 in the United States and as observed by d'Albis and Navaux (2016) between 1979 and 2011 in France. In this article, we compare per capita 
asset income received by retired people in France (aged 60 and over) that we would like to compare with adults (aged 18 to 59). Due to the bad quality of data after age 85 , we defined our indicator as follows:

$$
\frac{\text { income per capita for ages } 60-85}{\text { income per capita for ages } 18-59}
$$

We therefore consider only observations before age 85 .

The second indicator compares the asset income of successive generations at the same age. For this indicator, the standard of intergenerational equity requires that, at each age, every generation's asset income has to be at least equivalent to that of the previous generation (Bonnet, 2014). For instance, we ask ourselves whether the situation of the baby-boomers is better than the situation of the following generations at the same age. If this were the case, it would represent a break in intergenerational equity to the benefit of baby-boomers. However, this indicator is a minimum standard for intergenerational equity, because a period of economic growth should result mechanically in an improvement in the standard of living from one generation to another, as it had been shown in France for labor income, consumption, and public transfers (Navaux, 2016). This indicator must be completed by a more ambitious one.

The third indicator is a combination of the two previous criteria. It is, at the same time an inter-age indicator and an intergenerational indicator. It computes relative measures of asset income by dividing net resources at age $a$ and date $t$ by their cross-sectional average (Blanchet and Monfort, 2000). In this paper, we divide per capita asset income of persons aged $a$ at time $t$ with the average asset income of people aged 18 to 85 :

Per capita current asset income of persons aged $a$ at time $t$

Average of per capita asset income by age (unweighted by demography) of persons aged $18-85$ at time $t$

By calculating this ratio for each year, we are able to follow each generation over the 32-year time window (1979-2011). This is an inter-age indicator, because for a given year, the indicator reveals what age group is in the best position in comparison with the other age groups. This is also an intergenerational indicator because it is possible to determine whether a given birth cohort maintains a better position than its contemporaries over time. A golden generation would be a birth cohort that holds the best position over its entire lifecycle. This indicator is stronger than the second indicator because it is growth neutral in the sense that a generation can maintain a favored position over time even with high economic growth. It was not the case for the second indicator that depends mainly on GDP growth. 
The three indicators that we have selected do not cover all the possible ways to study intergenerational equity but provide a good coverage of the issue. Moreover, the period of 32 years that is available for France is not enough to construct age profiles for the complete life cycle of generations. Consequently, we cannot measure intergenerational equity indicators based on a balance sheet of several generations over their life cycle, as it would require overlapping generation models (Chojnicki et al., 2016) or generational accounting exercises (Kotlikoff, 1992). One way to overcome the difficulty is to build pseudo-cohorts as in d'Albis and Badji (2017).

\section{No large differences in monetary asset income between generations}

Figure 2 introduces the per capita age profiles normalized to 1 in Figure 2(a), which are computed such that the surface below the curve is equal to 1 , as well as the three intergenerational equity indicators in Figure 2(b), Figure 2(c), and Figure 2(d).

Figure 2(a) shows that the per capita normalized age profile remained stable over time for people between 40 and 75 years of age. However, the age profile diverged for younger and older people. After 75, the normalized age profile increased between 1979 and 1984, decreased between 1984 and 2000, and remained stable afterward. A symmetric evolution was observed for younger people between 18 and 40 years of age. Monetary asset income became strongly negative between 1979 and 1984, then increased up to 1995 , and remained quite stable thereafter. These fluctuations can be partly explained by the interest paid by individuals, most notably before 40 years of age. For instance, real interest rates on mortgages increased considerably between 1979 and 1985, then remained stable until 1992, when they began to decrease (Wilhelm, 2005).

The impact of the high interest rates in the 1980s also appears in Figure 2(b) which shows the ratio of per capita monetary asset income of people aged 60 to 85 to per capita monetary asset income of people aged 18 to 59. The ratio reaches a peak in 1984 because of the high interest rates paid by young people. In 1984, people aged 60 to 85 received 7.2 times the average monetary asset income of people aged 18 to 59. Thereafter, the ratio follows an L-shaped curve with the lowest point of 2.3 in 2003 . A second peak, of 3.2, is reached in 2008 and the ratio decreases slightly again after 2008. The high peak of 1984 draws our attention as it could indicate an imbalance between generations. In particular, one could ask whether a generation could have a lower monetary asset income than previous generations at the same age. Figure 2(c) describes the evolution of monetary asset income by birth cohort in constant euros. We assume that the evolution of monetary asset income is equitable for generations since a generation has 
a higher income than the previous generations at the same age. On the whole, Figure 2(c) shows that monetary asset income increases from one generation to another between 1979 and 2011. For instance, at age 40, people who were born in 1960 get more than two times the average constant monetary asset income of people who were born in 1950. At age 60, monetary asset income of people who were born in 1940 was $47 \%$ higher than people who were born in 1930 at the same age. D'Albis et al. (2017) showed that successive generations benefited from economic growth through labor income, and our results show that it was also the case for monetary asset income. Moreover, the figure shows a specificity for the 1950 and 1960 birth cohorts because these are the only generations who received a negative monetary asset income at young ages. The 1960 birth cohort reaches a minimum of - 203 constant euros in 1985 at age 25. This effect is even stronger for the 1950 birth cohort who receives a negative monetary asset income of -716 constant euros in 1982 at age 32 . We evidence once again the impact of high interest rates in the mid-1980s that did impact these generations just when they bought their first home. Figure 2(c) shows also that people who were born in 1980 had systematically lower asset income than people who were born in 1970 when we compare them at the same age, i.e. up to age 31 . The window of observation is rather small but it shows that this generation experienced a deteriorated situation at the beginning of its working life. Figure 2(d) is useful to assess if a generation has a better position than its contemporaries and how its position evolves over time. Three generational effects are revealed between 1979 and 2011. First, there exists a breakdown of intergenerational equity for the cohorts 1910 to 1930 . In fact, the 1910 cohort had a worse position than the 1900 cohort at each age, and the 1930 and 1920 cohorts had a worse position than the 1910 cohort at each age. ${ }^{11}$ Secondly, between age 40 years and age 70 , all the cohorts have the same relative position. It does evidence a fair distribution of monetary asset income for these age groups. Thirdly, the negative impact of high interest rates of the mid-1980s evidenced by figure 2 (a), figure $2(\mathrm{~b})$ and figure $2(\mathrm{c})$ is also very strong in figure 2(d). The 1950 birth cohort and the 1960 birth cohort had a worse position than the 1970 and the 1980 cohorts when they were young. After 40 , the two cohorts recovered a similar position to previous generations when we compare them at the same age.

In a nutshell, monetary asset income involves generational breaks between 1979 and 2011 but the babyboom generations did not benefit from their position over this period. On the contrary, the 1950 cohort experienced a difficult position when they were young by comparison with the 1960 and the 1970 cohorts. Finally, one should keep in mind the limitations of real estate income age profiles, since no

\footnotetext{
${ }^{11}$ Except between the 1910 cohort and the 1920 cohort after age 86.
} 
surveys are available between 1979 and 1985 and for 2011, and because real estate income represents a significant part of monetary asset income (25.5\% in 2011 , see table 1$)$.

Figure 2: Per capita monetary asset income between 1979 and 2011

(a) NTA normalized age profiles

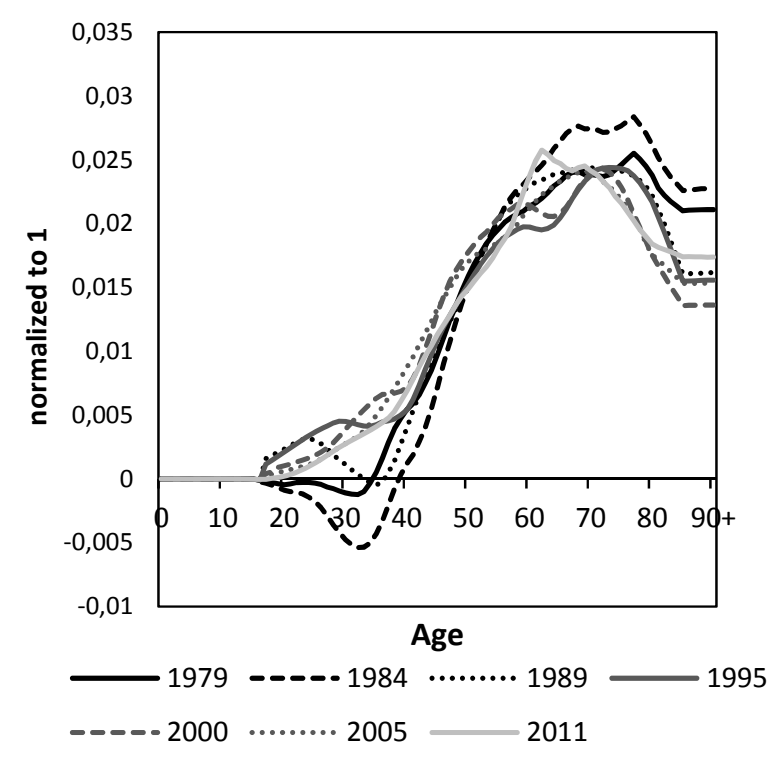

(c) Ind. 2: Cohort profiles

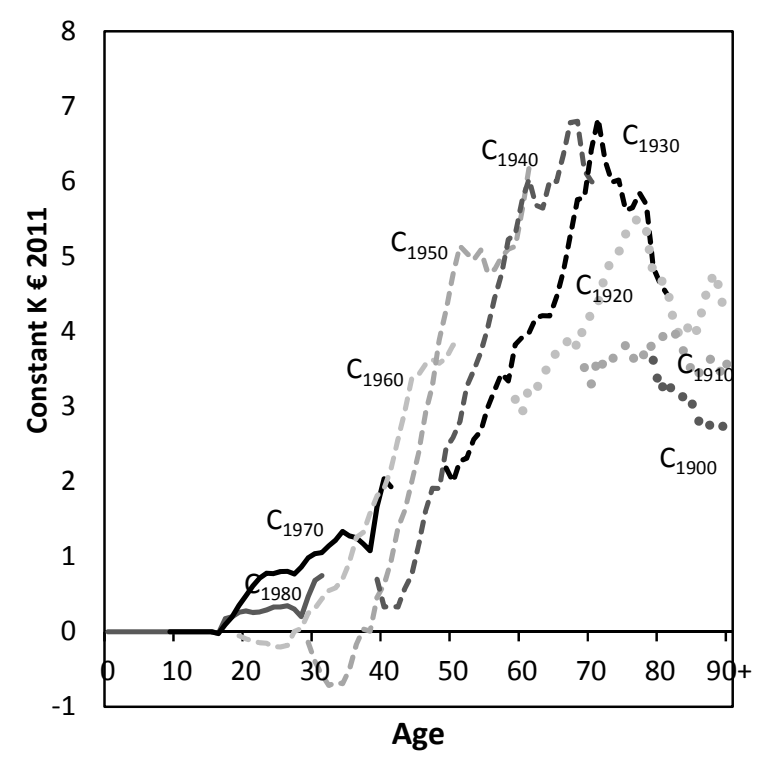

(b) Ind. 1: Ratio of asset income 60-85/18-59

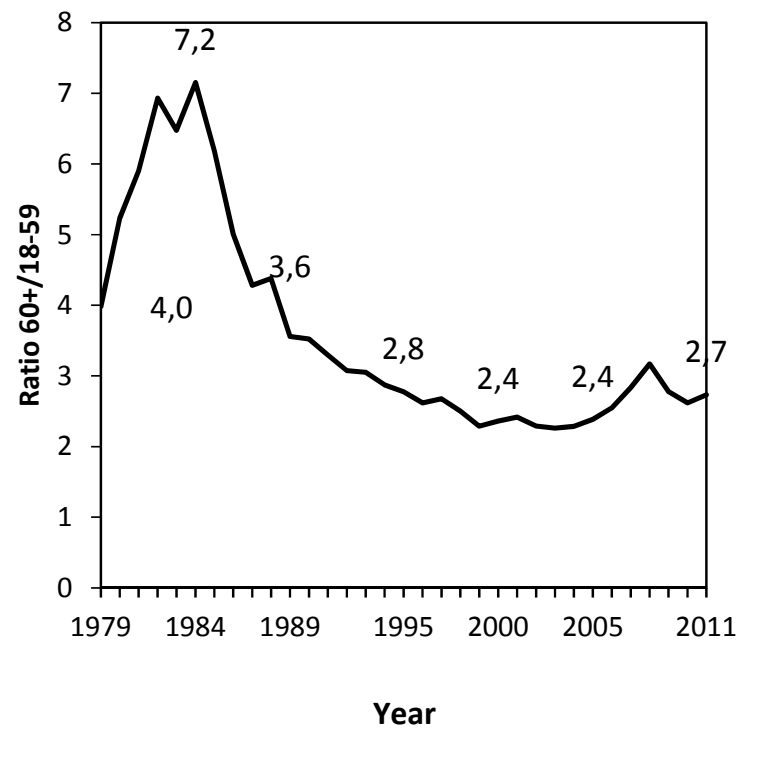

(d) Ind. 3: Inter-age and intergenerational indicator*

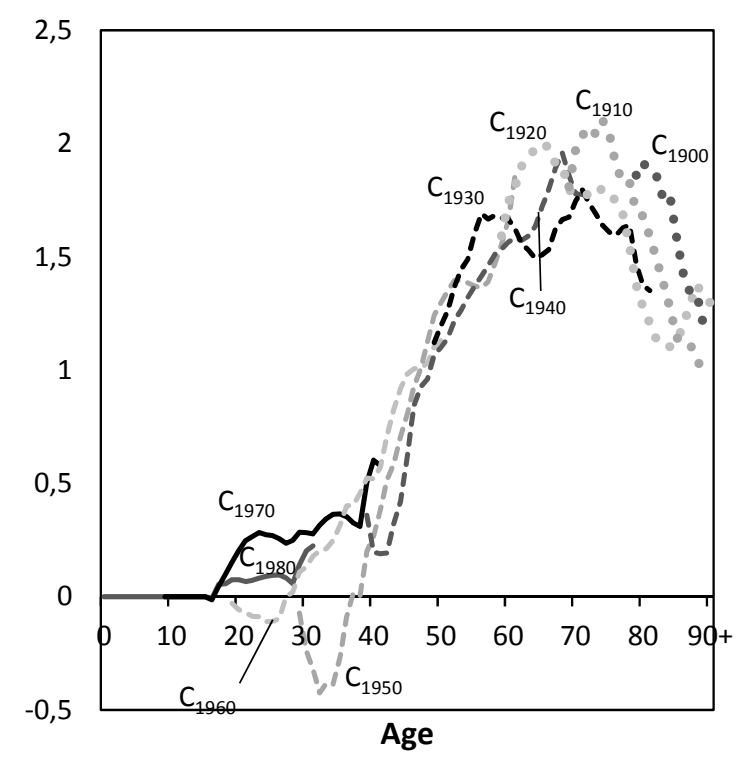

Note: " $C_{19 * *}$ " in figure 2 (c) and in figure 2 (d) refers to the birth cohorts.

* Ratio Per capita current asset income of persons aged $a$ at time $t$ 1979-2011 


\section{Significant generational effects for imputed rents}

The normalized age profiles presented in Figure 3(a) show that imputed rents follow two successive evolutions. ${ }^{12}$ First, imputed rents decrease over age after age 50 in 1979, in 1984, in 1989, and in 1995. For these four survey waves, the slope is less and less steep. In 2000, in 2005, and in 2011, the age profile increases after age 50 . This shift at older age could be explained by a significant increase in the ownership rate for people aged 60 and more after 1980. This increase is stronger after age 70 than between 60 and 70 (Bonvalet and Bringé, 2013). We find a similar dynamic in Figure 3(b), which represents the ratio of per capita imputed rents of people aged 60 to 85 to per capita imputed rents of people aged 18 to 59. In 1979, the per capita imputed rents of people aged 60 and over was equal to the per capita imputed rents of younger people. From 1979 to 2000, the ratio increased to 1.5 in 2000, which means that the per capita imputed rents of people aged 60 and over was $50 \%$ greater than the per capita imputed rents of people aged 18 to 59. Thereafter, the ratio decreases again to 1.3 in 2011 . The two successive movements of figure 2(b) can be explained by the situation of older individuals on the housing market, as we showed in figure 3(a), but also by the macroeconomic environment that impact the young. From the late 1970s to the late 1990s, young generations faced a substantial increase in housing prices (Friggit, 2011), high unemployment rates, and interest rates that were still high (Clerc et al., 2011). Consequently, young people endured a difficult macroeconomic environment that impacted their capacity to become homeowners (d'Albis and Djemaï, 2016). After 2000, the share of homeowners rose sharply for young people (especially between 25 and 35 years of age) because of low interest rates (Clerc et al., 2011), better income expectations (Gobillon and Le Blanc, 2004), and positive profit expectations due to increasing housing prices (Poterba, 1992). The share of homeowners also increased for people aged 60 and over but was not sufficient to compensate for the effect of interest rates on young people.

Fluctuations in the macroeconomic environment have an impact on imputed rents of generations and thus call into question intergenerational equity. Figure 3(c), which represents cohort profiles normalized in constant euros ${ }^{13}$, shows that imputed rents increase from one generation to another at the same age,

\footnotetext{
12 National Transfer Accounts include per capita imputed rents by age. Unfortunately, it does not provide any information about the price versus quality effects, which can both impact rent growth (Friggit, 2012).

${ }^{13}$ It would have been better to normalize the cohort profiles of Figure 3 (c) by using the index of the rents actually paid by tenants. INSEE produces this index, but only since 1990. Consequently, we chose to normalize the cohort profiles in constant euros with the Consumer Price Index (approximately 6\% of this index is composed of the rents actually paid).
} 
except from 2009 to 2011, when people aged 48 and over had lower imputed rents from one generation to another. First, imputed rents increased sharply between 1979 and 2009 for people born between 1900 and 1950 . When we compare them at the same age, imputed rents increased by $223 \%$ between the 1900 and 1910 cohorts, they increased by $165 \%$ between the 1920 and 1930 cohorts, and by 109\% between the 1940 and the 1950 cohorts $^{14}$. Imputed rents increased slowly from the 1950 cohort to the 1960 cohort, and even more slowly between the 1960 cohort and the 1970 cohort. Imputed rents stagnated between the 1970 cohort and the 1980 cohort: they increased only by $2.97 \%$ in constant euros between 18 and 31 years of age.

Figure $3(\mathrm{~d})$ indicates whether a generation systematically holds a favored position for the entire period compared to other generations at the same ages. We identified several generational breaks between 1979 and 2011. According to our third intergenerational equity indicator, the 1910 and 1930 cohorts benefit from a better situation than the generation born ten years before, except for certain ages. Thus, there is a clear generational break at the expense of older generations. The cohorts born in 1930 and 1940 seem to have a similar situation because their curves almost overlap between ages 49 and 71 . Moreover, for most of the years, those generations have a better situation than the previous generations and the following generations when we compare them at the same age. It appears that these generations occupied an even better situation than baby-boomers born in 1950. In fact, people born in 1950 have a better situation than the cohorts born in 1960 and 1970 at each age ${ }^{15}$. The difference seems to be significant between the baby-boomers born in 1950 and younger people at the same age, but it also significant between the 1950 cohort and the previous generations. The generations born between 1960 and 1980 have a similar situation at the same age, which demonstrates a relative equity between them. Thus, the cohort born in 1950 indeed benefited from a favored position compared to their successors but also had a worse situation between ages 35 to 50 compared to cohorts born in 1940 and 1930, which appear to be the most favored generations. This relative situation on the housing market does not imply a higher standard of living as measured by consumption or revenues including imputed rents (d'Albis and Badji, 2017).

\footnotetext{
${ }^{14}$ We compare cohorts in the same age groups, depending on the available data between 1979 and 2011 . We compare the cohorts 1900 and 1910 after 79 years old, the cohorts 1920 and 1930 between 59 and 81 years old and the cohorts 1940 and 1950 between 39 and 61 years old.

${ }^{15}$ Except between the cohorts 1950 and 1960 at 49 years old and 50 years old.
} 
Figure 3: Per capita imputed rent income between 1979 and 2011

(a) NTA normalized age profiles

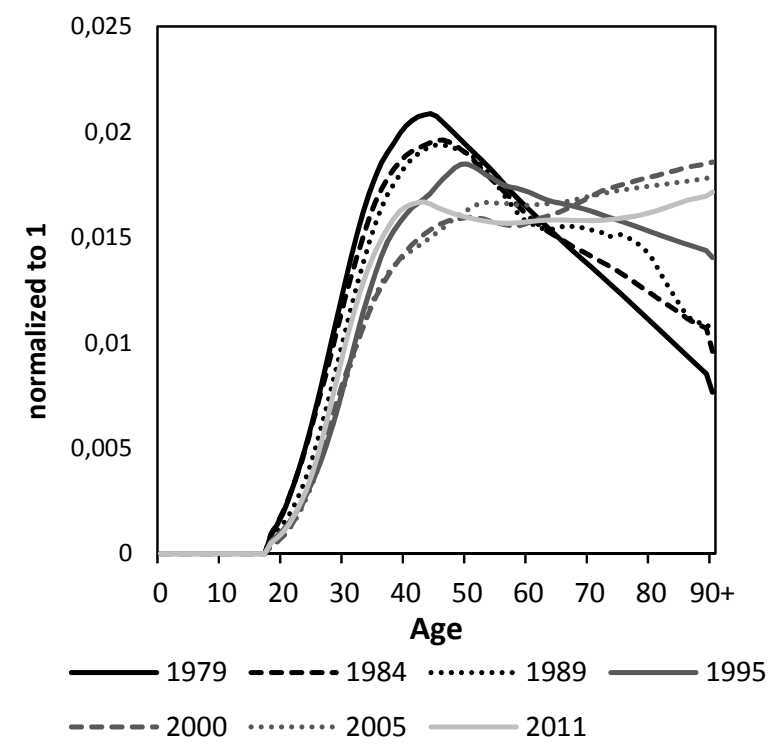

(c) Ind. 2: Cohort profiles

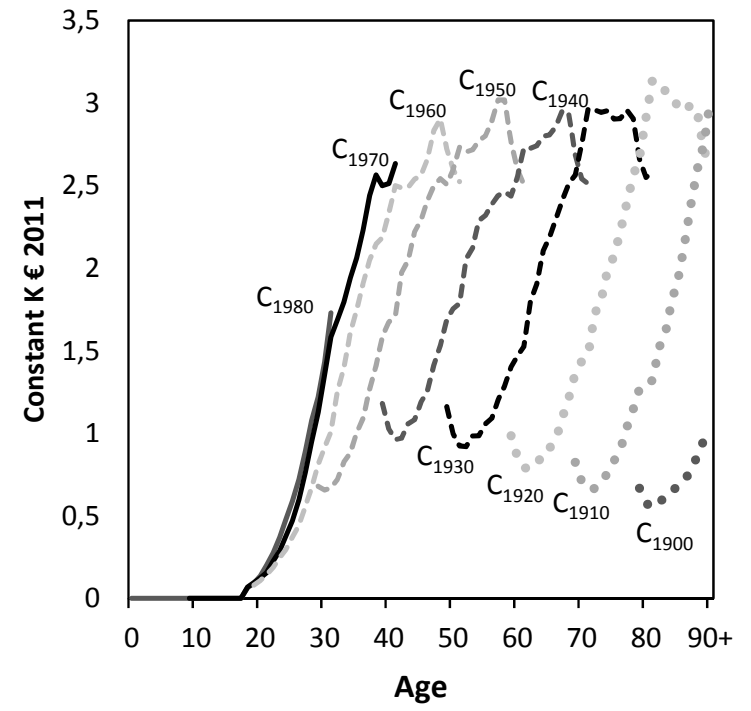

(b) Ind. 1: Ratio of imputed rent income $60+/ 18-59$

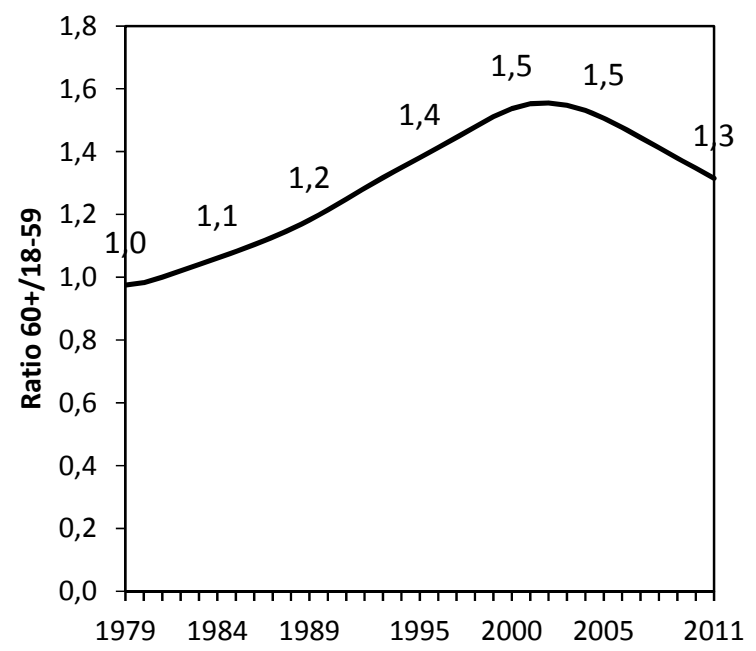

Year (d) Ind. 3: Inter-age and intergenerational indicator*

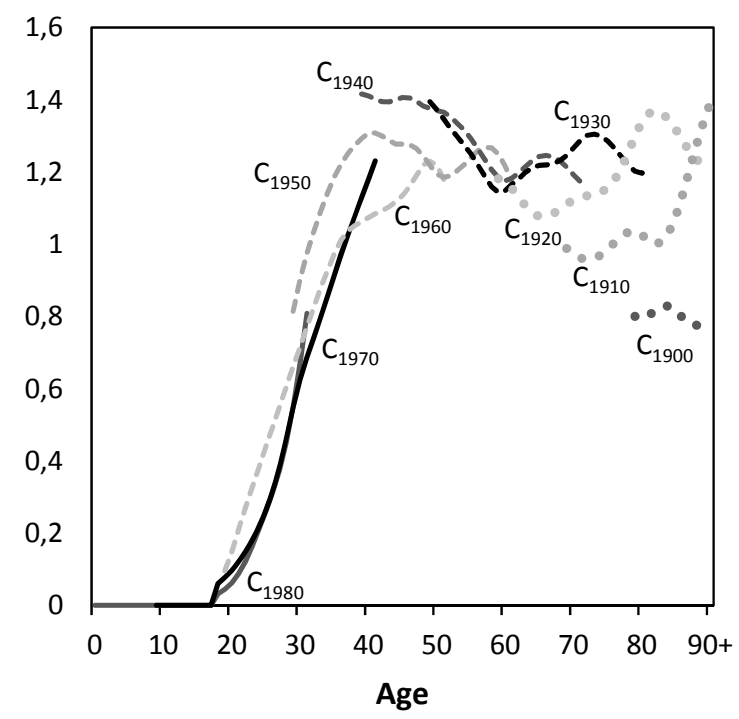

Note: " $C_{19 * *}$ " in figure $3(c)$ and in figure $3(d)$ refers to the birth cohorts.

* Ratio $\frac{\text { Per capita current asset income of persons aged } a \text { at time } t}{\text { Average of per capita asset income by age (unweighted by demography) of people aged 18-85 at time } t}, 1979-2011$

Finally, Figure 4 represents the third indicator but the complete private asset income: monetary asset income plus imputed rents. It does not show any break in equity between the 1950 cohort and the 
generations that followed. This is due to the prevailing impact of interest rates that exceeds the impact of imputed rents for the 1950 cohort. On the whole, this cohort received a lower asset income than the 1960 cohort, the 1970 cohort, and the 1980 cohort at each age between 1979 and 2011. Figure 4 also reveals that monetary asset income tends to hide all the other generational breakdowns that were evidenced for imputed rents when we consider total asset income.

\section{Figure 4: Per capita private asset income between 1979 and 2011}

\section{Ind. 3: Inter-age and intergenerational indicator*}

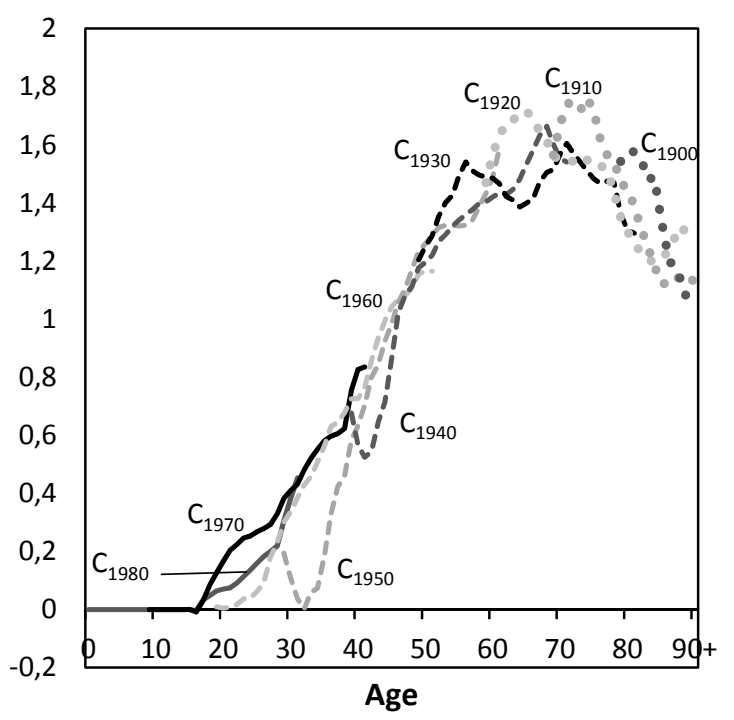

* Ratio $\frac{\text { Per capita current asset income of persons aged } a \text { at time } t}{\text { Average of per capita asset income by age (unweighted by demography) of people aged 18-85 at time } t}, 1979-2011$

\section{Conclusion}

In France, several studies have been conducted recently on intergenerational equity. They demonstrate that baby-boomers were not favored with regard to the allocation of consumption, of labor income, of public transfers, and of financial assets (d'Albis et al., 2017; d'Albis and Badji, 2017; Chojnicki et al., 2016; Navaux, 2016; Bernard and Berthet, 2015). Our paper extends this conclusion to monetary asset income. We show that baby-boomers didn't benefit from a favored position in comparison with the other generations, because they suffered from the high interest rates of the 1980's. The cohort born in 1950 received strong negative monetary asset income when they were young adults, while the next generations had slightly negative or slightly positive monetary asset income at the same age.

On the contrary, imputed rents imply several breaks of intergenerational equity when we follow the relative position of each generation with respect to their contemporaries over time. First, the cohort born 
in 1950 systematically holds a better position than the cohorts born in 1960 and in 1970. It reflects the high housing prices that young generations faced from the late 1970's to the late 1990's, combined with high unemployment rates and high interest rates. However, it does not mean that the cohort born in 1950 is a golden generation, because the generations born in 1930 and in 1940 appear to be much more favored than the baby-boomers. They benefited from a better position than the previous generations and the following generations when we compare them at the same age.

Although there is no evidence of any generational break to the benefit of baby-boomers for actual economic flows, our results for imputed rents reveal an important issue about wealth. We know from (Piketty, 2014) that the share of wealth in National Income and the share of wealth transfer in National Income increased significantly since World War II and that it might strengthen over the coming years. Therefore, our current research focuses on an extension of National Transfer Accounts to wealth accounts, following the primary works of (Lee, 1994). We will also carry out an update of economic flow accounts up to 2017 with the next Budget Survey that should be available in 2018. Moreover, asset income is highly concentrated on top income deciles. This process is reinforced since wealth is more and more concentrated, particularly because of the growing economic weight of inheritance (Piketty, 2014). Consequently, National Transfer Accounts by income level are necessary to assess whether birth cohorts of each income decile improved their situation with respect to the previous generations that were in the same income decile. It is nevertheless necessary to create a new NTA methodology since macroaggregates are not available for income deciles. 


\section{References}

Arrondel L., Bachellerie A., Birouk O., Chaput H., Savignac F. (2011), "Les comportements patrimoniaux des ménages en France: Évolutions et déterminants entre 2004 et 2010", Bulletin de la Banque de France, no. 185, pp. 89-107.

Askenazy P., Cette G., Sylvain A. (2011), Le partage de la valeur ajoutée, Paris: La Découverte.

Becker G.S., Murphy K.M. (1988), "The Family and the State", Journal of Law and Economics, vol. 31(1), pp. 1-18.

Bernard J. B., Berthet L. (2015), "French households financial wealth: which changes in 20 years?", working paper no. G2015/18, INSEE.

Blanchet D. (1998), "Mesurer l'équité intergénérationnelle: Le choix des indicateurs", La lettre de l'Observatoire des Retraites, no. 10 - Retraite et équité entre générations.

Blanchet D., Monfort J.A. (2000), "Pension and Generational Histories in a Simple Demo-economic Model: the Case of France", in Mason A. and Tapinos G. (eds.), Sharing the Wealth, Demographic Change and Economic Transfers between Generations, New York: Oxford University Press, pp. 170-194.

Bonnet C. (2014), « Un inévitable conflit des générations ? ", Informations sociales, vol. 183(3), pp. 136144.

Bonvalet C., Bringé A. (2013), «Les effets de la politique du logement sur l'évolution du taux de propriétaires en France », Revue européenne des sciences sociales, vol. 51(1), pp. 153-177.

Chojnicki X., Navaux J., Ragot L. (2016), “L'impact des réformes des retraites sur l'équité entre générations", in Lorenzi J. H. (dir.), Choc démographique, rebond économique, Collection Chaire Transitions Démographiques, Transitions Économiques, Descartes et Cie, pp. 167-191.

Clerc M. E., Monso O., Pouliquen E. (2011), "Les inégalités entre générations depuis le baby-boom", INSEE Références.

Conseil d'Orientation des Retraites (2017), Évolutions et perspectives des retraites en France, Rapport annuel du COR - Juin.

D’Albis H., Badji I. (2017), "Intergenerational inequalities in standards of living in France”, Economics and Statistics, vol. 491-492, pp. 71-92. 
D’Albis H., Bonnet C., Navaux J., Pelletan J., Toubon H., Wolff F.C. (2015), "The Lifecycle Deficit for France, 1979-2005", Journal of the Economics of Ageing, vol. 5, pp. 79-85.

D’Albis H., Bonnet C., Navaux J., Pelletan J., Wolff F.C. (2017), "Lifecycle deficit in France: an assessment for the period 1979-2011", Economics and Statistics, vol. 491-492, pp. 47-70.

D’Albis H., Djemaï, E. (2016), "Evolutions démographiques et marché de l'immobilier neuf", Revue $d^{\prime}$ Economie Régionale et Urbaine, to appear.

D'Albis H., Moosa D. (2015), "Generational Economics and the National Transfer Accounts", Journal of Demographic Economics, vol. 81, pp. 409-441.

D’Albis H., Navaux J. (2016), "La répartition par âge des transferts publics en France", in Lorenzi J.H. (dir.), Choc démographique, rebond économique, Collection Chaire TDTE, Descartes et Cie, pp. 319-331.

Donehower G., Lee R.D., Miller T. (2011), "The changing shape of the economic lifecycle in the United States, 1960 to 2003", in Lee R.D., Mason A. (eds.), Population Aging and the Generational Economy: A Global Perspective, Northampton, Massachusetts: Edward Elgar, pp. 313-326.

Friedman J.H. (1984), "A variable span scatterplot smoother, Laboratory for Computational Statistics", Stanford University Technical Report no. 5.

Friggit J. (2011), "Quelles perspectives pour le prix des logements après son envolée?", Regards croisés sur l'économie, Paris: La Découverte, vol. 9, pp. 14-32.

Friggit J. (2012), "Mission sur les aides personnelles au logement", Note de fin de mission, Conseil général de l'Environnement et du Développement durable, mission no. 007987-01.

Gobillon L., Le Blanc D. (2004), "L'impact des contraintes d'emprunt sur la mobilité résidentielle et les choix entre location et propriété", Annales d'Economie et de Statistique, no. 74, pp. 15-45.

Kotlikoff L.J. (1992), Generational Accounting. Knowing Who Pays, and When, for What We Spend, The Free Press, Macmillan, New York, 220 p.

Lai M.S., Tung A. C. (2015), "Who supports the elderly? The changing economic lifecycle reallocation in Taiwan, 1985 and 2005", Journal of the Economics of Ageing, vol. 5, pp. 63-68.

Lee R.D. (1994), “Population Age Structure, Intergenerational Transfer, and Wealth: A New Approach, with Applications to the United States", The Journal of Human Resources, Vol. 29(4), Special Issue: The Family and Intergenerational Relations, pp. 1027-1063. 
Lee R.D., Mason A., eds., (2011a), Population Aging and the Generational Economy: A Global Perspective, Northampton, Massachusetts: Edward Elgar.

Lee R.D., Mason A. (2011b), "Generational Economics in a Changing World", Population and Development Review, 37 (S1) (2011), pp. 115-142

Lindh T., Oeberg G., Sanchez-Romero M. (2011), “Back-casting National Transfer Accounts in Sweden from 1800 to 2009", paper presented at the 4th European NTA Workshop, Budapest.

Navaux J. (2016), "Intergenerational transfers in France: Stable trends and breaks between age groups", Ph.D. thesis, Paris Dauphine University, 247 p.

Piketty T (2014), Capital in the 21st century, Harvard University Press, 698 p.

Poterba J.M. (1992), "Taxation and Housing: Old Questions, New Answers", The American Economic Review, vol. 82, no. 2, Papers and Proceedings of the Hundred and Fourth Annual Meeting of the American Economic Association, pp. 237-242.

Temple J. B., Rice J.M., McDonald P.F. (2017), “Mature Age Labour Force Participation and the Life Cycle Deficit in Australia: 1981-82 to 2009-10", The Journal of the Economics of Ageing, 10, 21-33.

United Nations (2013), National Transfer Accounts manual: Measuring and analysing the generational economy, Department of Economic and Social Affairs, Population Division, p. 224.

Wilhelm F. (2005), "L'évolution actuelle du crédit à I’habitat en France est-elle soutenable ? Bulletin de la Banque de France $n^{\circ} 140$. 